\title{
GEOMETRIK TEMPAT PARKIR PESAWAT UDARA BANDAR UDARA FATMAWATI SOEKARNO DI KOTA BENGKULU
}

\author{
Anggita Yuliani \\ MSTT FT UGM \\ Universitas Gadjah Mada \\ Jln. Grafika 2, Senolowo \\ Sinduadi, Kecamatan Mlati \\ Kabupaten Sleman \\ Daerah Istimewa Yogyakarta \\ anggitayuliani@mail.ugm.ac.id
}

\author{
Latif Budi Suparma \\ MSTT FT UGM \\ Universitas Gadjah Mada \\ Jln. Grafika 2, Senolowo \\ Sinduadi, Kecamatan Mlati \\ Kabupaten Sleman \\ Daerah Istimewa Yogyakarta \\ lbsuparma@ugm.ac.id
}

\author{
Suprapto Siswosukarto \\ MSTT FT UGM \\ Universitas Gadjah Mada \\ Jln. Grafika 2, Senolowo \\ Sinduadi, Kecamatan Mlati \\ Kabupaten Sleman \\ Daerah Istimewa Yogyakarta \\ suprapto.siswosukarto@ugm.ac.id
}

\begin{abstract}
Flight services at Fatmawati Soekarno Airport, located in Bengkulu City, continue to develop, along with the increasing public need for air transportation. The increasing need for aviation services affects the number and types of aircraft required. Aircraft maneuvering and parking affect the dimensions of the aircraft parking space. In this study, an analysis of the dimensions of the apron at Fatmawati Soekarno Airport was carried out, with a service life of 20 years. The analysis in this study was carried out using the design aircraft B737-900ER. The existing apron dimension lot is $475 \mathrm{~m}$ long and $80 \mathrm{~m}$ wide. By using the International Civil Aviation Organization method and the Federal Aviation Administration method, to accommodate aircraft movements for the next 20 years, an apron with a length of $475 \mathrm{~m}$ and a width of $100 \mathrm{~m}$ is required. Thus, the width of the existing apron must be increased by $20 \mathrm{~m}$, in order to be able to serve the B737-900ER aircraft until the service life of the next 20 years.
\end{abstract}

Keywords: airport; flight services; apron; air transport.

\begin{abstract}
Abstrak
Layanan penerbangan di Bandar Udara Fatmawati Soekarno, yang terletak di Kota Bengkulu, terus mengalami perkembangan, seiring dengan meningkatnya kebutuhan masyarakat akan transportasi udara. Peningkatan kebutuhan akan layanan penerbangan tersebut memengaruhi jumlah dan jenis pesawat udara yang diperlukan. Pesawat udara yang melakukan manuver dan parkir memengaruhi dimensi tempat parkir pesawat udara. Pada studi ini dilakukan analisis terhadap dimensi tempat parkir pesawat udara di Bandar Udara Fatmawati Soekarno, dengan umur layanan 20 tahun. Analisis pada studi ini dilakukan dengan menggunakan pesawat udara rencana B737-900ER. Tempat parkir pesawat udara eksisting mempunyai panjang $475 \mathrm{~m}$ dengan lebar $80 \mathrm{~m}$. Dengan menggunakan metode International Civil Aviation Organization da metode Federal Aviation Administration, untuk melayani pesawat udara hingga 20 tahun mendatang diperlukan tempat parkir pesawat udara dengan panjang $475 \mathrm{~m}$ dan lebar $100 \mathrm{~m}$. Dengan demikian lebar tempat parkir pesawat udara eksisting harus ditambah $20 \mathrm{~m}$, agar dapat melayani pesawat udara tipe B737-900ER hingga umur layanan 20 tahun mendatang.
\end{abstract}

Kata-kata kunci: bandar udara; layanan penerbangan; tempat parkir pesawat udara; transportasi udara.

\section{PENDAHULUAN}

Bandar Udara Fatmawati Soekarno merupakan satu-satunya bandar udara di Kota Bengkulu. Bandar udara ini dikelola oleh PT Angkasa Pura II. Pelayanan rute penerbangan di bandar udara ini adalah penerbangan domestik yang terus mengalami perkembangan 
seiring dengan meningkatnya kebutuhan masyarakat Kota Bengkulu akan kegiatan penerbangan. Hal ini seiring dengan bertumbuhnya perekonomian masyarakat Kota Bengkulu pada tahun 2019, yang mengalami peningkatan sebesar 4,79\% dibandingkan dengan tahun sebelumnya (BPS Kota Bengkulu, 2019). Peningkatan kebutuhan masyarakat akan kegiatan penerbangan tersebut memengaruhi banyaknya pesawat udara yang dibutuhkan, sehingga diperlukan perluasan sisi udara, baik landasan pacu (runway) maupun tempat parkir pesawat udara (apron).

Pesawat udara terbesar yang beroperasi di Bandar Udara Fatmawati Soekarno adalah Airbus 320 dan Boeing 737. Banyaknya pesawat udara yang parkir dan melakukan manuver memengaruhi luasan tempat parkir pesawat udara. Sejalan dengan peningkatan kebutuhan, diperlukan analisis untuk masa yang akan datang, agar tempat parkir pesawat udara dapat tetap melayani pesawat udara yang akan parkir dengan pesawat udara yang lebih besar, agar dapat menampung jumlah penumpang yang lebih banyak selama umur layan 20 tahun mendatang.

Geometrik tempat parkir pesawat udara harus dapat disesuaikan dengan kondisi pesawat udara yang akan parkir, sehingga perlu dilakukan evaluasi dan analisis geometrik. Metode Federal Aviation Administration (FAA) dan Metode International Civil Aviation Organization (ICAO) merupakan metode-metode yang digunakan untuk menentukan luasan yang dibutuhkan oleh pesawat udara untuk parkir, serta sebagai parameter kelayakan pelayanan tempat parkir pesawat udara di Bandar Udara Fatmawati Soekarno, Kota Bengkulu.

\section{METODE PENELITIAN}

Pengumpulan data primer dilakukan dengan survei langsung ke lapangan berupa dokumentasi lapangan dan wawancara. Sedangkan pengumpulan data sekunder dilakukan di Bandar Udara Fatmawati Soekarno, Kota Bengkulu, pada PT Angkasa Pura II Kota Bengkulu, selaku operator bandara. Metode FAA dan metode ICAO dipilih untuk melakukan analisis pada penelitian ini, dengan tahapan-tahapan seperti yang diuraikan oleh Sartono et al (2016).

Perhitungan volume lalu lintas didasarkan pada data lalu lintas pesawat udara pada tahun-tahun sebelumnya, selama 10 tahun. Selanjutnya dilakukan analisis menggunakan metode time series untuk menentukan faktor pertumbuhan lalu lintas. Selanjutnya, berdasarkan hasil ini, dilakukan forecasting untuk menentukan prediksi pergerakan pesawat udara hingga 20 tahun mendatang.

Perhitungan jam puncak pesawat dan penumpang digunakan untuk mengetahui jumlah pesawat udara yang akan beroperasi selama jam puncak. Hal ini dimaksudkan agar pesawat udara tidak saling menunggu, yang menyebabkan adanya antrian parkir pesawat udara.

Penentuan gate occupancy time dilakukan untuk mengetahui jumlah pergerakan pesawat udara per jam yang dapat dilayani berdasarkan tipe pesawat udara yang digunakan. 
Gate occupancy time ditentukan dengan menggunakan metode ICAO dan FAA pada tabel yang telah disediakan.

Dimensi tempat parkir pesawat udara dirancang dengan menggunakan metode ICAO dan metode FAA, sesuai dengan tipe pesawat udara yang digunakan. Perhitungan dimensi tempat parkir pesawat udara digunakan untuk mengetahui pelayanan arus lalu lintas maksimum yang diperlukan pada suatu bandar udara.

\section{HASIL DAN PEMBAHASAN}

\section{Data Umum Bandar Udara Fatmwati Soekarno}

Bandar Udara Fatmawati Soekarno merupakan bandar udara kelas IB domestik, dengan Aerodrome Reference Code 4C dan aircraft stand sebanyak (7-8) pesawat udara (Dinas Perhubungan Kota Bengkulu, 2020). Luas lahan eksisting yang ada sekitar 197.929 Ha dan lahan pengembangan sekitar 68.040 Ha. Kondisi eksisting tempat parkir pesawat udara dapat dilihat pada Gambar 1.

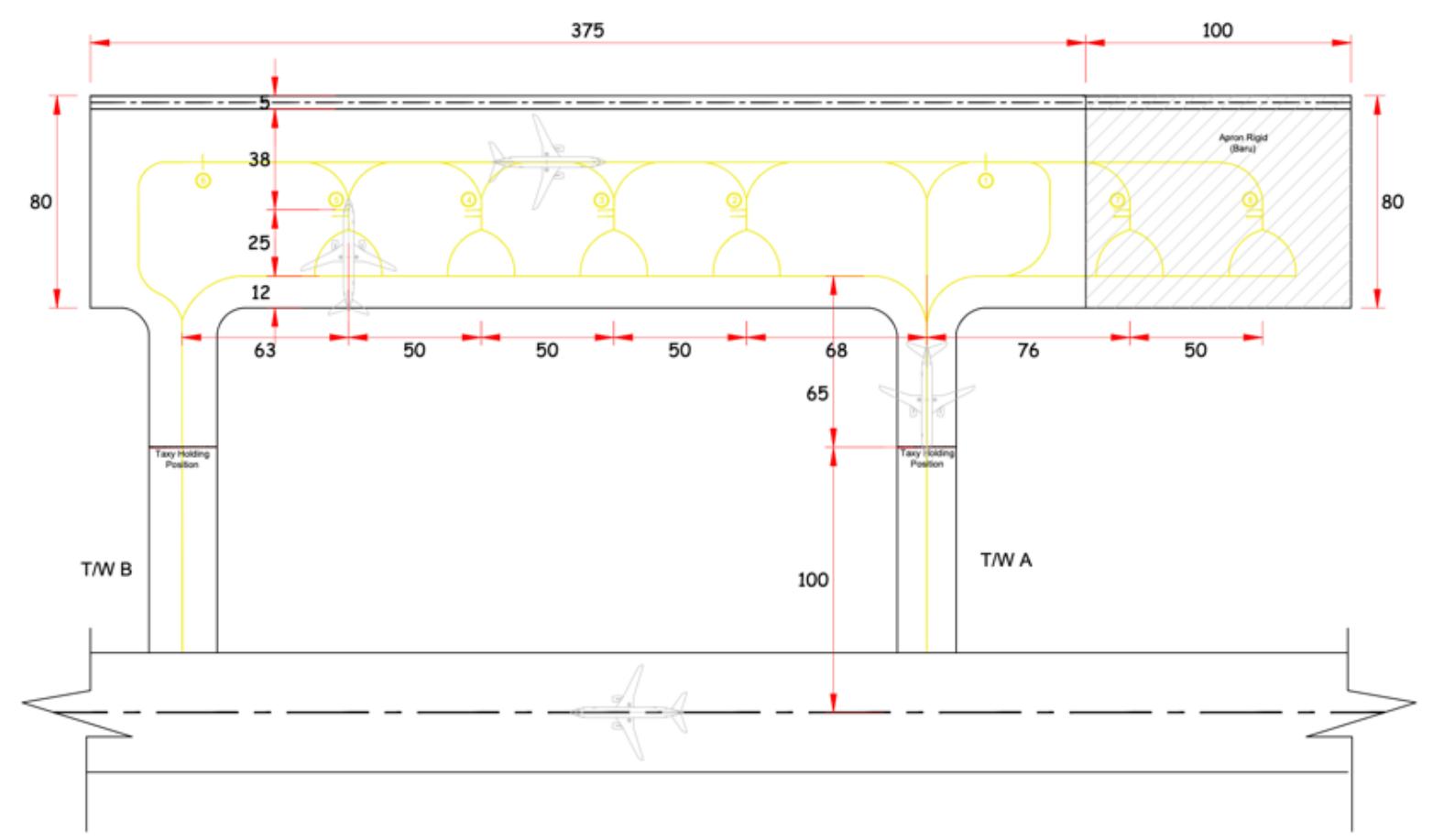

Gambar 1 Kondisi Eksisting Tempat Parkir Pesawat Udara di Bandar Udara Fatmawati Soekarno

\section{Data Lalu Lintas Udara}

Data lalu lintas udara yang digunakan adalah data lalu lintas udara 10 tahun terakhir, yaitu pada tahun 2010-2019. Data tahun 2020 tidak digunakan, karena adanya pandemi Covid-19, yang menyebabkan adanya pemberhentian sementara perjalanan moda-moda transportasi, yang memengaruhi pergerakan pesawat udara dan penumpang. Data pergerakan 
pesawat udara dan penumpang tahun 2010 hingga 2019 dapat dilihat pada Tabel 1 (Angkasa Pura II, 2020).

Tabel 1 Pergerakan Pesawat Udara dan Penumpang Tahun 2010 Hingga Tahun 2019

\begin{tabular}{ccccc}
\hline \multirow{2}{*}{ Tahun } & \multicolumn{2}{c}{ Pesawat } & \multicolumn{2}{c}{ Penumpang } \\
\cline { 2 - 5 } & Datang & Berangkat & Datang & Berangkat \\
\hline 2010 & 2.444 & 2.442 & 269.068 & 274.110 \\
2011 & 2.413 & 2.413 & 287.048 & 290.046 \\
2012 & 2.538 & 2.538 & 334.118 & 333.236 \\
2013 & 2.781 & 2.781 & 350.853 & 355.814 \\
2014 & 3.458 & 3.456 & 375.171 & 385.615 \\
2015 & 3.688 & 3.676 & 402.914 & 412.321 \\
2016 & 4.032 & 4.043 & 468.436 & 441.750 \\
2017 & 4.529 & 4.544 & 510.975 & 499.631 \\
2018 & 4.861 & 4.860 & 531.156 & 536.283 \\
2019 & 3.999 & 3.998 & 381.545 & 392.769 \\
\hline
\end{tabular}

Data pada Tabel 1 menunjukkan bahwa pergerakan pesawat udara dan jumlah penumpang Bandar Udara Fatmawati Soekarno mengalami peningkatan setiap tahun. Namun pada tahun 2019 mengalami penurunan, karena pada akhir tahun 2019, Covid-19 telah mulai menyebar, sehingga mulai dilakukan pengetatan perjalanan, baik menggunakan transportasi darat, transportasi laut, maupun transportasi udara. Namun penurunan pergerakan pesawat udara dan penumpang pada tahun 2019 tidak terlalu signifikan, sehingga data tahun 2019 masih digunakan untuk memprediksi jumlah pergerakan pesawat udara dan penumpang untuk waktu 20 tahun mendatang.

\section{Prediksi Data Lalu Lintas 20 Tahun Mendatang}

Prediksi lalu lintas 20 tahun mendatang diperlukan untuk memperkirakan jumlah pergerakan pesawat udara dan penumpang, sebagai dasar untuk melakukan analisis pelayanan kebutuhan masyarakat Kota Bengkulu dalam menggunakan moda transportasi udara. Peramalan dilakukan dengan menggunakan data lalu lintas keberangkatan pesawat udara, karena data tersebut memengaruhi kondisi geometrik bandar udara, eksisting maupun untuk 20 tahun mendatang.

Untuk keperluan peramalan, analisis data lalu lintas keberangkatan pesawat udara dilakukan dengan menggunakan metode model regresi dengan data time series, yang menggunakan persamaan linier dan persamaan exponential smoothing sebagai pembanding. Hasil analisis memberikan persamaan linier:

$$
y=273,75 x+1.969,47 ; \text { dengan } R^{2}=0,8525
$$

dan persamaan exponential smoothing:

$$
\mathrm{y}=2.153,1 \mathrm{e}^{0,0814 \mathrm{x}} ; \text { dengan } \mathrm{R}^{2}=0,8729
$$


Hasil peramalan untuk 20 tahun mendatang dapat dilihat pada Tabel 2. Berdasarkan hasil peramalan yang terdapat pada Tabel 2, dipilih persamaan exponential smoothing, karena mempunyai nilai koefisien determinasi $\left(\mathrm{R}^{2}\right)$ yang lebih besar. Jumlah keberangkatan pesawat udara tahun 2039 adalah 24.752 pesawat udara.

Tabel 2 Hasil Peramalan Keberangkatan Pesawat Udara

\begin{tabular}{lccc}
\hline \multirow{2}{*}{ Tahun } & \multirow{2}{*}{ Periode Ke } & \multicolumn{2}{c}{ Perkiraan Jumlah Keberangkatan Pesawat Udara } \\
\cline { 3 - 4 } 2020 & 11 & 4.981 & Persamaan Exponential Smoothing \\
2021 & 12 & 5.254 & 5.271 \\
2022 & 13 & 5.528 & 5.719 \\
2023 & 14 & 5.802 & 6.204 \\
2024 & 15 & 6.076 & 6.730 \\
2025 & 16 & 6.349 & 7.300 \\
2026 & 17 & 6.623 & 7.919 \\
2027 & 18 & 6.897 & 8.591 \\
2028 & 19 & 7.171 & 9.320 \\
2029 & 20 & 7.444 & 10.110 \\
2030 & 21 & 7.718 & 10.967 \\
2031 & 22 & 7.992 & 11.897 \\
2032 & 23 & 8.266 & 12.906 \\
2033 & 24 & 8.540 & 14.001 \\
2034 & 25 & 8.813 & 15.188 \\
2035 & 26 & 9.087 & 16.476 \\
2036 & 27 & 9.361 & 17.874 \\
2037 & 28 & 9.635 & 19.389 \\
2038 & 29 & 9.908 & 21.034 \\
2039 & 30 & 10.182 & 22.817 \\
& & & 24.752 \\
\hline
\end{tabular}

\section{Jumlah Pesawat Udara 20 Tahun Mendatang}

Jumlah pesawat yang akan beroperasi pada 20 tahun mendatang diperoleh dengan menganalisa pergerakan pesawat udara pada jam sibuk, dengan merumuskan terlebih dahulu nilai koefisien permintaan angkutan lalu lintas pada jam sibuk tersebut. Selanjutnya dilakukan perhitungan jumlah pesawat udara yang akan parkir di tempat parkir pesawat udara. Nilai Gate Occupancy Time (T) suatu pesawat udara dipengaruhi oleh nilai turnaround flight pesawat udara tersebut, yang untuk pesawat udara B737-900ER adalah 45 menit (ICAO, 1987). Dengan demikian Gate Occupancy Time (T) pesawat udara B737900ER adalah 45 menit.

Selanjutnya dihitung jumlah pesawat udara yang akan parkir di tempat parkir pesawat udara pada jam puncak. Hasil perhitungan dapat dilihat pada Tabel 3. Jumlah pesawat udara yang parkir di tempat parkir pesawat udara pada jam puncak pada tahun 2010 hingga tahun 2039 dapat dilihat pada Tabel 3. Terlihat bahwa pada tahun 2039, jumlah pesawat udara yang akan parkir pada tempat parkir pesawat udara Bandar Udara Fatmawati Soekarno adalah 11 pesawat udara. Pada kondisi eksisting, tempat parkir pesawat udara ini hanya mampu menampung 8 pesawat udara. Dengan demikian perlu dilakukan penambahan lahan parkir pesawat udara, sehingga dapat menampung pesawat udara pada jam sibuk di 20 tahun mendatang. 
Tabel 3 Perhitungan Jumlah Pesawat Udara yang Parkir

\begin{tabular}{|c|c|c|c|c|c|}
\hline Tahun & $\begin{array}{c}\text { Jumlah } \\
\text { Keberangkatan } \\
\text { Pesawat }\end{array}$ & $M_{d}$ & $C_{p}$ & $M_{p}$ & $N$ \\
\hline 2010 & 2.442 & 6,69 & 0,53 & 4 & 4 \\
\hline 2011 & 2.413 & 6,61 & 0,54 & 4 & 4 \\
\hline 2012 & 2.538 & 6,95 & 0,52 & 4 & 4 \\
\hline 2013 & 2.781 & 7,62 & 0,50 & 4 & 4 \\
\hline 2014 & 3.456 & 9,47 & 0,45 & 4 & 4 \\
\hline 2015 & 3.676 & 10,07 & 0,43 & 4 & 4 \\
\hline 2016 & 4.043 & 11,08 & 0,41 & 5 & 4 \\
\hline 2017 & 4.544 & 12,45 & 0,39 & 5 & 5 \\
\hline 2018 & 4.860 & 13,32 & 0,38 & 5 & 5 \\
\hline 2019 & 3.998 & 10,95 & 0,42 & 5 & 4 \\
\hline 2020 & 5.271 & 14,44 & 0,36 & 5 & 5 \\
\hline 2021 & 5.719 & 15,67 & 0,35 & 5 & 5 \\
\hline 2022 & 6.204 & 17,00 & 0,33 & 6 & 5 \\
\hline 2023 & 6.730 & 18,44 & 0,32 & 6 & 5 \\
\hline 2024 & 7.300 & 20,00 & 0,31 & 6 & 6 \\
\hline 2025 & 7.919 & 21,70 & 0,30 & 6 & 6 \\
\hline 2026 & 8.591 & 23,54 & 0,28 & 7 & 6 \\
\hline 2027 & 9.320 & 25,53 & 0,27 & 7 & 6 \\
\hline 2028 & 10.110 & 27,70 & 0,26 & 7 & 6 \\
\hline 2029 & 10.967 & 30,05 & 0,25 & 8 & 7 \\
\hline 2030 & 11.897 & 32,60 & 0,24 & 8 & 7 \\
\hline 2031 & 12.906 & 35,36 & 0,23 & 8 & 7 \\
\hline 2032 & 14.001 & 38,36 & 0,22 & 9 & 7 \\
\hline 2033 & 15.188 & 41,61 & 0,21 & 9 & 8 \\
\hline 2034 & 16.476 & 45,14 & 0,21 & 9 & 8 \\
\hline 2035 & 17.874 & 48,97 & 0,20 & 10 & 9 \\
\hline 2036 & 19.389 & 53,12 & 0,19 & 10 & 10 \\
\hline 2037 & 21.034 & 57,63 & 0,18 & 10 & 10 \\
\hline 2038 & 22.817 & 62,51 & 0,17 & 11 & 10 \\
\hline 2039 & 24.752 & 67,81 & 0,17 & 11 & 11 \\
\hline
\end{tabular}

\section{Perancangan Geometrik Tempat Parkir Pesawat Udara}

Perancangan geometrik tempat parkir pesawat udara dilakukan dengan menggunakan metode ICAO dan metode FAA. Untuk itu perlu ditentukan dimensi tempat parkir untuk satu tipe pesawat udara, yang untuk studi ini adalah pesawat udara B737-900ER, pada 20 tahun mendatang. Dimensi pesawat udara B737-900ER dapat dilihat pada Gambar 2 (Boeing Commercial Airplanes, 2020).

Tabel 4 Jarak Bebas Minimum di Tempat Parkir Pesawat Udara (ICAO, 2013)

\begin{tabular}{cccc}
\hline \multirow{2}{*}{$\begin{array}{c}\text { Aerodrome } \\
\text { Code Letter } \\
\text { (ICAO) }\end{array}$} & $\begin{array}{c}\text { Between Aircraft and Fixed } \\
\text { or Movable Objects }\end{array}$ & $\begin{array}{c}\text { Aircraft Stand Taxilane } \\
\text { Centre Line to Object, } \\
(\mathrm{B})\end{array}$ & $\begin{array}{c}\text { Apron Taxiway Centre } \\
\text { Line to Object, } \\
(\mathrm{A})\end{array}$ \\
\hline $\mathrm{A}$ & $3,0 \mathrm{~m}$ & $12,0 \mathrm{~m}$ & $16,25 \mathrm{~m}$ \\
$\mathrm{~B}$ & $3,0 \mathrm{~m}$ & $16,5 \mathrm{~m}$ & $21,5 \mathrm{~m}$ \\
\hline $\mathrm{C}$ & $4,5 \mathrm{~m}$ & $24,5 \mathrm{~m}$ & $26,0 \mathrm{~m}$ \\
\hline $\mathrm{D}$ & $7,5 \mathrm{~m}$ & $36,0 \mathrm{~m}$ & $40,5 \mathrm{~m}$ \\
$\mathrm{E}$ & $7,5 \mathrm{~m}$ & $42,5 \mathrm{~m}$ & $47,5 \mathrm{~m}$ \\
$\mathrm{~F}$ & $7,5 \mathrm{~m}$ & $50,5 \mathrm{~m}$ & $57,5 \mathrm{~m}$ \\
\hline
\end{tabular}


Perancangan luasan tempat parkir pesawat udara ditentukan dengan menggunakan Tabel 4 (ICAO, 2005) dan Tabel 5 (FAA, 1998). Dengan menggunakan kriteria tersebut diperoleh dimensi yang sesuai dengan jarak untuk kode huruf (code letter) yang dipersyaratkan.

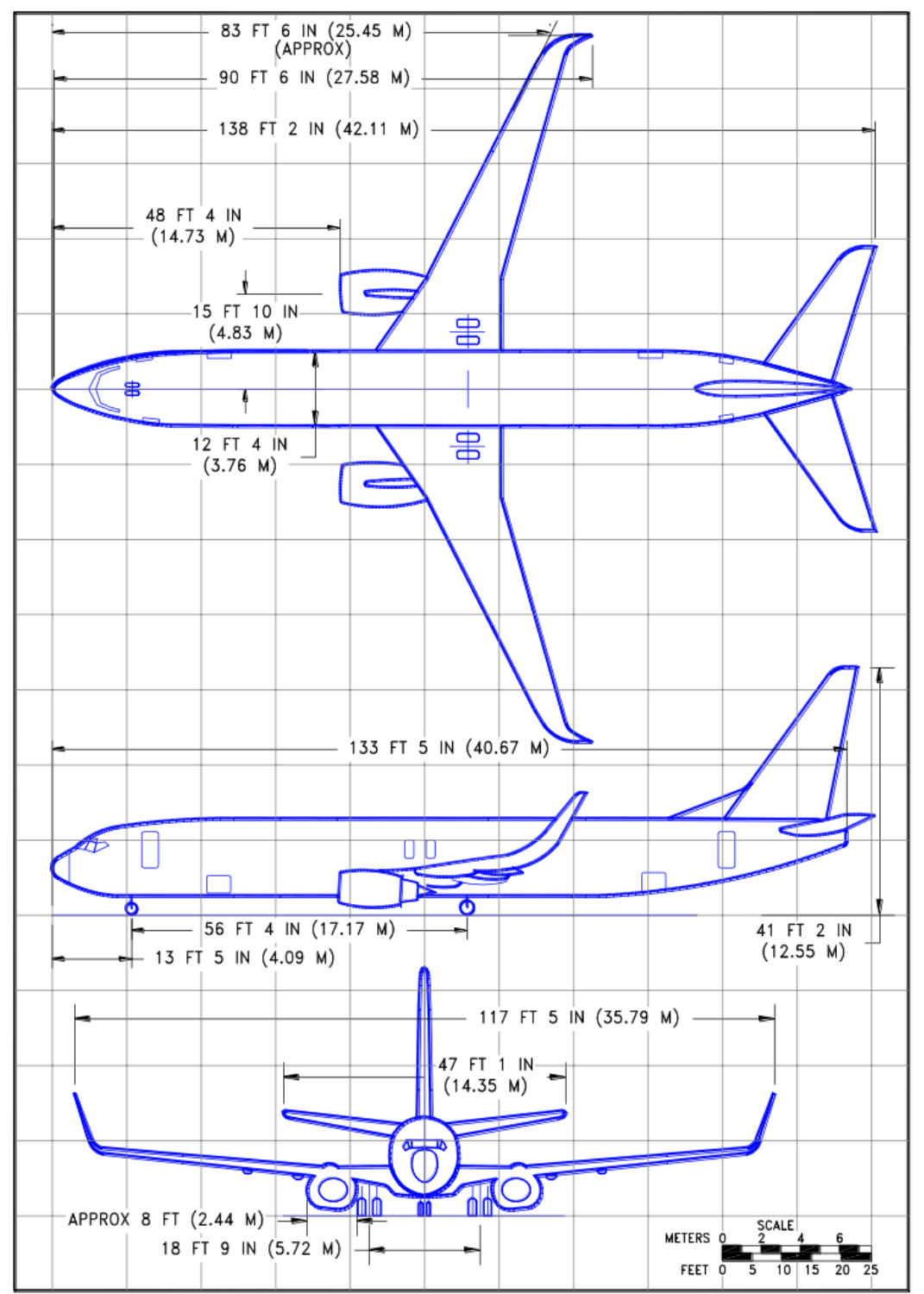

Sumber: Boeing Commercial Airplanes (2020)

Gambar 2 Dimensi Pesawat Udara B737-900ER

Tabel 5 Jarak Bebas Minimum di Tempar Parkir Pesawat Udara Menurut FAA

\begin{tabular}{cccc}
\hline $\begin{array}{c}\text { Code Letter } \\
(\mathrm{FAA})\end{array}$ & Nose to Building Clearance & $\begin{array}{c}\text { Between Aircraft and Fixed or } \\
\text { Movable Objects }\end{array}$ \\
\hline $\mathrm{A}$ & $30 \mathrm{ft}$ & $9,0 \mathrm{~m}$ & $15 \mathrm{ft}$ \\
$\mathrm{B}$ & $20 \mathrm{ft}$ & $6,0 \mathrm{~m}$ & $25 \mathrm{ft}$ \\
\hline $\mathrm{C}$ & $20 \mathrm{ft}$ & $6,0 \mathrm{~m}$ & $25 \mathrm{ft}$ \\
\hline $\mathrm{D}$ & $15 \mathrm{ft}$ & $4,5 \mathrm{~m}$ & $25 \mathrm{ft}$ \\
$\mathrm{E}$ & $15 \mathrm{ft}$ & $4,5 \mathrm{~m}$ & $25 \mathrm{ft}$ \\
\hline
\end{tabular}


Sebagaimana telah dihitung sebelumnya, jumlah pesawat udara yang akan parkir di tahun 2039 adalah 11 pesawat udara. Dari perhitungan diperoleh panjang tempat parkir pesawat udara adalah 451,9 m atau dibulatkan menjadi $475 \mathrm{~m}$, dengan lebar 90,67 m, atau dibulatkan menjadi $100 \mathrm{~m}$. Dimensi tempat parkir pesawat udara di Bandar Udara Fatmawati Soekarno pada 20 tahun, untuk melayani pesawat udara B737-900ER sebanyak 11 pesawat udara pada jam sibuk dapat dilihat pada Gambar 3.

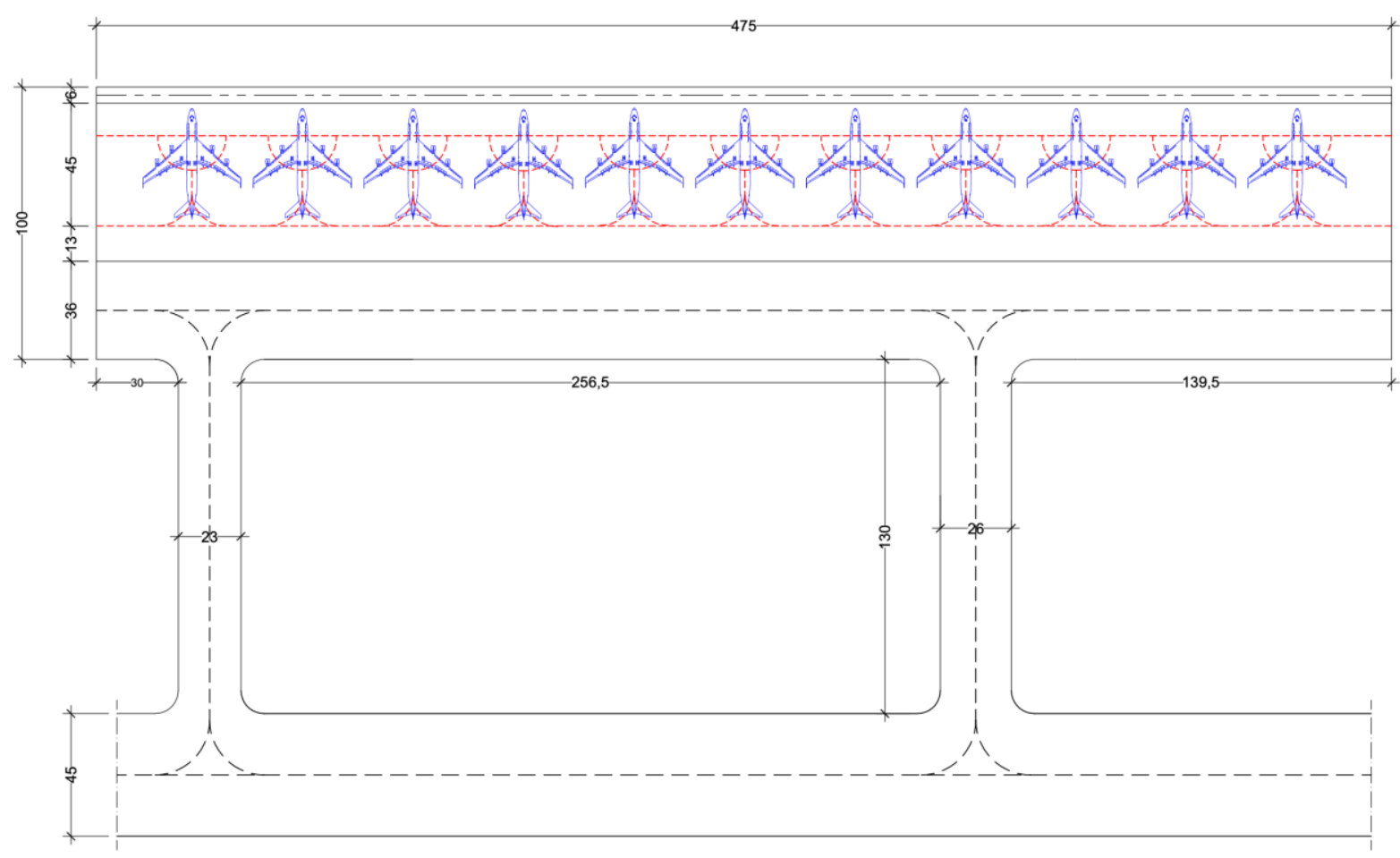

Gambar 3 Dimensi Tempat Parkir Pesawat Udara Bandar Udara Fatmawati Soekarno 20 Tahun Mendatang

Tempat parkir pesawat udara eksisting memiliki konfigurasi parkir pesawat udara yang berbeda-beda. Konfigurasi parkir pesawat udara Pada aircraft stand 1 dan aircraft stand 6 adalah paralel, sedangkan konfigurasi parkir pada aircraft stands 2,3,4,5,7, dan 8 adalah hidung ke dalam (nose-in). Pada studi ini dilakukan desain tempat parkir pesawat udara yang lebih efisien, dengan menggunakan konfigurasi parkir pesawat udara linier tipe hidung ke dalam, dengan pesawat udara parkir tegak lurus dan berjarak dekat dengan gedung terminal. Konfigurasi linier ini menghasilkan jembatan pemuatan dan posisi parkir pesawat udara yang merata, yang biasanya secara operasional lebih efisien, karena manuver pushback pesawat udara menjadi minimal (Ricondo and Associates, Incorporated, 2013). Hal ini dilakukan karena dengan konfigurasi tersebut luasan yang diperlukan lebih kecil dan tingkat kebisingan lebih rendah, karena tidak ada jet blast yang mengarah ke bangunan terminal. Konfigurasi parkir pesawat udara tipe nose-in ini juga memudahkan penumpang untuk masuk ke dalam dan keluar dari pesawat udara, dan diharapkan nantinya gedung terminal memiliki garbarata, sehingga penumpang dapat langsung terhubung dengan pesawat udara. 
Dimensi eksisting tempat parkir pesawat udara di Bandar Udara Fatmawati adalah $475 \mathrm{~m}$ x $80 \mathrm{~m}$. Untuk kondisi 20 tahun mendatang, dibutuhkan tempat parkir pesawat udara dengan dimensi $475 \mathrm{~m}$ x $100 \mathrm{~m}$, sehingga perlu dilakukan penambahan dimensi tempat parkir pesawat udara tersebut. Berdasarkan kondisi lahan yang ada, pengembangan lebar tempat parkir pesawat udara dapat dilakukan dengan mengambil $20 \mathrm{~m}$ dari panjang taxiway eksisting.

\section{KESIMPULAN}

Studi ini membahas tempat parkir pesawat udara di Bandar Udara Fatmawati Soekarno, yang terletak di Kota Bengkulu. Dimensi tempat parkir pesawat udara direncanakan dapat menampung jumlah pesawau udara untuk 20 tahun ke depan.

Pada kajian ini, direncanakan bandar udara akan melayani pesawat udara tipe B737300ER. Hasil perhitungan menunjukkan bahwa luasan tempat parkir pesawat udara yang dibutuhkan untuk 20 tahun ke depan adalah $47500 \mathrm{~m}^{2}$, dengan panjang $475 \mathrm{~m}$ dan lebar $100 \mathrm{~m}$.

Tempat parkir pesawat udara eksisting mempunyai panjang $475 \mathrm{~m}$ dengan lebar $20 \mathrm{~m}$. Hal ini berarti bahwa panjang tempat parkir pesawat udara eksisting dapat dipertahankan, tetapi lebarnya harus ditambah dengan $20 \mathrm{~m}$.

\section{DAFTAR PUSTAKA}

Angkasa Pura II. 2020. Informasi Umum Bandar Udara Fatmawati Soekarno Kota Bengkulu. Bengkulu.

Badan Pusat Statistik (BPS) Kota Bengkulu. 2019. Jumlah Lalu Lintas Provinsi Bengkulu. Bengkulu.

Boeing Commercial Airplanes. 2020. Airplane Characteristics for Airport Planning. Seattle, WA.

Dinas Perhubungan Kota Bengkulu. 2020. Detail Bandar Udara Fatmawati Soekarno Kota Bengkulu. Bengkulu.

Federal Aviation Administration (FAA). 1998. Planning and Design Guidelines for Airport Terminal Facilities. FAA Advisory Circular AC/150/5360-13. Washington, DC.

International Civil Aviation Organization (ICAO). 2005. Aerodrome Design Manual Part 2: Taxiways, Aprons and Holding Bays. Montreal.

International Civil Aviation Organization (ICAO). 1987. Airport Planning Manual. Montreal. 
Ricondo and Associates, Incorporated. 2013. Apron Planning and Design Guidebook. Chicago, IL.

Sartono, W., Dewanti, dan Rahman, T. 2016. Bandar Udara: Pengenalan dan Perancangan Geometrik Runway, Taxiway, dan Apron. Yogyakarta: UGM Press. 